\title{
Serial antinuclear antibodies titre in pleural and pericardial fluid
}

\author{
D-Y. Wang*, P-C. Yang**, W-L. Yu*, S-H. Kuo ${ }^{\# \#, ~ N-Y . ~ H s u ~}{ }^{+}$
}

Serial antinuclear antibodies titre in pleural and pericardial fluid. D-Y. Wang, P-C. Yang, W-L. Yu, S-H. Kuo, N-Y. Hsu. (C)ERS Journals Ltd 2000.

ABSTRACT: The antinuclear antibodies (ANA) test has been a cornerstone of the evaluation of connective tissue disease. The aim of this study was to investigate the diagnostic value of the ANA test in pleural or pericardial effusions of unknown causes.

Over a 3-yr period, a total of 126 pleural fluid and 30 pericardial fluid samples were analysed. ANA tests were performed using a commercially available kit. The ANA kit used an indirect immunofluorescent antibody method with a human epithelial (HEP2) cell line as substrate. Patients with high fluid ANA titre $(>1: 160)$ received a second aspiration 2 weeks after the initial aspiration if diagnosis was not confirmed.

ANA results were positive in 39 pleural and 10 pericardial fluid samples. All but one of the effusions with positive ANA testing were exudative. Eleven pleural or pericardial effusions due to active systematic lupus erythematosus were identified and all had high ANA titres (1:160) with various staining patterns. Thirty-eight of 145 patients $(26 \%)$ with effusions of nonlupus aetiologies had positive ANA testing in pleural or pericardial fluid. Thirteen of these 38 patients had high ANA titre. Malignant or paramalignant effusions constituted 11 of the 13 samples.

In conclusion, although a negative antinuclear antibodies test makes a diagnosis of lupus serositis unlikely, high antinuclear antibodies titres in pleural or pericardial fluid are not diagnostic of lupus serositis even when as high as 1:5,120. An unexplained high antinuclear antibodies titre in pleural or pericardial effusion warrants search for malignancy.

Eur Respir J 2000; 15: 1106-1110.
*Division of Chest and Cytopathology, ${ }^{\#}$ Dept of Internal Medicine, and ${ }^{+}$Dept of Chest surgery, China Medical College Hospital Medical Center, Taichung, Republic of China. **Dept of Internal Medicine and ${ }^{\# \text { Clinical Cytopathology, National Taiwan }}$ University Hospital, Taipei, Taiwan, Republic of China.

Correspondence: D.Y. Wang Division of Chest and Cytopathology Dept of Internal Medicine China Medical College Hospital No. 75, Yuh Der Road, Taichung 404 Taiwan, Republic of China. Fax: 886 42582960 .

Keywords: Antinuclear antibodies pericardial effusion

pleural effusion

Received: June 301999

Accepted after revision February 72000
The antinuclear antibodies test (ANA) is frequently used as a screening test for autoimmune disease [1]. By using substrate antigen derived from an animal cell line, a positive pleural fluid ANA test was considered diagnostic of lupus erythematosus (LE) pleurisy $[2,3]$. Recent studies have reported that the presence of high pleural fluid ANA titres were also seen occasionally in patients with inflammatory pleural effusions in the absence of LE pleurisy $[4$, 5]. However, the diagnostic value of positive pleural fluid ANA titre other than inflammatory pleurisy is still not clear and the significance of pericardial fluid ANA has never been reported $[1,6]$.

Pleural and pericardial fluid samples were prospectively collected from 1996-1999 at China Medical College Hospital $(\mathrm{CMCH})$ Medical Centre (Taichung, China), and performed ANA tests using the human epithelial HEP-2 cell line. The aim of the study was to evaluate the significance of pleural fluid and pericardial fluid ANA titres in patients with various diseases. The clinical usefulness of ANA staining patterns and fluid to serum ANA ratios was also evaluated.

\section{Materials and methods}

During the period from 1996-1999, effusions (pleural, pericardial) of initially unknown aetiology were studied in hospitalized patients at $\mathrm{CMCH}$ Medical Centre. The effusions were aspirated under echo guidance and the aspirated fluid samples were sent for laboratory analysis. If no definite diagnosis was made or effusion persisted in spite of treatment, a second aspiration was performed 2 weeks later. Laboratory analyses of fluid samples included biochemical study (protein, amylase, glucose and lactate dehydrogenase), PH, complete blood count, bacterial culture, cytology and ANA testing. An effusion was determined to be an exudate if one of the following criteria was present: 1) fluid to serum protein ratio $>0.5 ; 2$ ) fluid to serum lactate dehydrogenase (LDH) ratio $>0.6$; or 3 ) fluid LDH greater than two-thirds of the upper limits of normal. Effusions not meeting any of these criteria were considered transudates [4].

Over a 3-yr period, 30 cases of pericardial effusion and 150 cases of pleural effusion were collected. Twenty-four pleural effusions were excluded because laboratory data were not available in seven patients and a cause for the pleural effusion could not be determined in 17 patients who refused invasive diagnostic procedures. Thus, a total of 126 pleural fluid and 30 pericardial fluid samples were analysed. Patients with high fluid ANA titre (1:160) received a second aspiration 2 weeks after the initial aspiration if diagnosis was not confirmed. Final diagnosis was made in all 156 patients. The mean age was 48 yrs (10-85 yrs). Fluid samples were randomly numbered and ANA tests were performed using a commercially available kit (Medical and Biological Laboratories Co. Ltd., Tokyo, Japan). The ANA kit used an indirect immunofluorescent antibody method with the HEP-2 cell line as substrate. All specimens were screened at a 1:40 dilution in phosphatebuffered saline and, if positive, were retested at greater 
dilutions. Immunofluorescence was considered positive if observed at titres of $\geq 1: 40$. The aspirated fluid samples were routinely stained by Popanicolaou's stain, Liu's stain and immunochemical methods as have been previously described $[7,8]$. The cytological smears and histological sections were reviewed by two independent pathocytologists. With their permission, most of the patients with unexplained pleural effusion or pericardial effusion underwent Tru-cut biopsy or surgical exploration. Procedures of aspiration and biopsy were performed by ultrasound guidance according to previous studies $[9,10]$.

\section{Results}

Of the 126 pleural fluid samples and 30 pericardial fluid samples, a positive ANA was detected in 39 and 10 respectively (table 1). All but one of the fluid samples with a positive ANA titre were exudative. The ANA negative samples were also exudative except the congestive heart failure and myxoedema groups. The cause of only one patient with positive ANA titre and transudative pleural effusion was congestive heart failure. The ANA titre in this patient was low (1:40) with speckled pattern. As shown in table 1, the miscellaneous group included pleural effusions due to drug allergy, subphrenic abscess, ankylosing spondylitis, chylothorax, amebiasis, hypersensitivity pneumonitis, Meigs' syndrome and pericardial fluid due to Dressler's syndrome. Of the samples diagnosed with one of the above conditions, only one pleural fluid sample had a positive ANA titre (amebiasis empyema with positive ANA titre 1:160).

Fifteen patients with systemic (S)LE and pleural or pericardial effusion were identified (table 2). Pleural or pericardial effusion due to active lupus was confirmed in 11 of the 15 patients (patients 1-11). The causes of the other four SLE patients with effusion were parapneumonic (patients 12, and 13) and congestive heart failure (patients 14 and 15). Negative or low pleural fluid ANA

Table 1. - Antinuclear antibodies test results of pleural and pericardial fluid

\begin{tabular}{lcc}
\hline $\begin{array}{l}\text { Causes of pleural } \\
\text { effusions } \\
\text { or pericardial } \\
\text { effusions }\end{array}$ & $\begin{array}{c}\text { No. of pleural } \\
\text { samples } \\
\text { (NO. of } \\
\text { positive ANA) }\end{array}$ & $\begin{array}{c}\text { No. of pericardial } \\
\text { fluid samples } \\
\text { (No. of } \\
\text { positive ANA) }\end{array}$ \\
\hline $\begin{array}{l}\text { Systemic lupus } \\
\text { erythematosus }\end{array}$ & $7(7)$ & $4(4)$ \\
Malignant & $33(12)$ & $4(2)$ \\
Paramalignant & $15(8)$ & $4(2)$ \\
Tuberculosis & $16(4)$ & $8(1)$ \\
Congestive heart failure & $11(1)$ & $0(0)$ \\
Parapneumonic & $17(4)$ & $0(0)$ \\
Empyema & $11(2)$ & $0(0)$ \\
Myxoedema & $2(0)$ & $1(0)$ \\
Virus & $0(0)$ & $4(1)$ \\
Pulmonary embolism & $3(0)$ & $0(0)$ \\
End-stage uraemia & $3(0)$ & $4(0)$ \\
Miscellaneous & $8(1)$ & $1(0)$ \\
Total & $126(39)$ & $30(10)$ \\
\hline
\end{tabular}

Miscellaneous group of pleural fluid includes one drug allergy, one subphrenic abscess, one ankylosing spondylitis, two chylothorax, one amebiasis, one hypersensitivity pneumonitis, and one Meigs' syndrome. titres $(\leq 1: 80)$ were noted in patients $12-15$. Patients $1-11$ with lupus pleuritis or pericarditis had high ANA titres $(\geq 1: 160)$ results and only five of them had a homogenous staining pattern. The pleural or pericardial fluid to serum ANA ratio was $\geq 1$ in only five of the 11 patients with lupus pleuritis or pericarditis.

The diagnosis of SLE was established prior to the acute serositis episode in 11 of the 15 patients. Patients $8,9,10$ and 11 had no history of SLE. Patients 8,9 and 11 presented with acute pleuritis, fever, cough, leukocytosis and predominance of polymorphonuclear cells in pleural fluid. Parapneumonic effusion was initially considered. Patient 8 received chest tube drainage due to clinical evidence of empyema (sugar $<40 \mathrm{~g} \cdot \mathrm{dL}^{-1}, \mathrm{LDH}>1000 \mathrm{U} \cdot \mathrm{L}^{-1}$ ). The patient also received abdominal tapping due to massive ascites. However, there was no clinical response after parenteral antibiotic treatment for 1 week. High pleural and ascitic fluid ANA titres were reported and SLE was later confirmed. Patient 10 initially presented with fever, dyspnoea and pericardial effusion of unknown cause. Positive pericardial fluid ANA and clinical investigation later confirmed the diagnosis of lupus pericarditis. Response to cortisone therapy was striking and led to rapid resorption of the effusion.

Patient 1 was a victim of SLE with sudden onset of pleurisy of unknown cause. Tuberculous pleuritis was initially suspected due to elevated adenosine deaminase

Table 2. - Clinical data of pleural and pericardial effusions due to systemic lupus erythematosus

\begin{tabular}{|c|c|c|}
\hline $\begin{array}{l}\text { Case No./ } \\
\text { Age/Sex }\end{array}$ & $\begin{array}{l}\text { Sources } \\
\text { of samples }\end{array}$ & $\begin{array}{l}\text { ANA titre } \\
\text { and pattern }\end{array}$ \\
\hline \multirow[t]{2}{*}{$1 / 30 / \mathrm{F}$} & Serum & 1:2560 Peripheral \\
\hline & Pleura & 1:2560 Homogenous \\
\hline \multirow[t]{2}{*}{$2 / 51 / \mathrm{F}$} & Serum & 1:320 Homogenous \\
\hline & Pleura & 1:640 Speckled \\
\hline \multirow[t]{2}{*}{$3 / 56 / \mathrm{F}$} & Serum & 1:160 Speckled \\
\hline & Pleura & 1:320 Speckled \\
\hline \multirow[t]{2}{*}{$4 / 63 / F$} & Serum & 1:1280 Homogenous \\
\hline & Pleura & 1:640 Homogenous \\
\hline \multirow[t]{2}{*}{$5 / 35 / F$} & Serum & 1:2560 Speckled \\
\hline & Pericardial & 1:640 Speckled \\
\hline \multirow[t]{3}{*}{$6 / 32 / \mathrm{F}$} & Serum & 1:640 Speckled \\
\hline & Pericardial & 1:640 Speckled \\
\hline & Pleura & 1:640 Speckled \\
\hline \multirow[t]{2}{*}{ 7/22/M } & Serum & 1:2560 Homogenous \\
\hline & Pericardial & 1:1280 Homogenous \\
\hline \multirow[t]{3}{*}{$8 / 18 / \mathrm{F}$} & Serum & 1:1280 Speckled \\
\hline & Pleura & 1:1280 Speckled \\
\hline & Ascites & 1:640 Speckled \\
\hline \multirow[t]{2}{*}{ 9/20/M } & Serum & 1:2560 Homogenous \\
\hline & Pleura & 1:1280 Homogenous \\
\hline \multirow[t]{2}{*}{$10 / 26 / F$} & Serum & 1:320 Homogenous \\
\hline & Pericardial & 1:160 Homogenous \\
\hline \multirow[t]{2}{*}{$11 / 80 / \mathrm{M}$} & Serum & 1:640 Speckled \\
\hline & Pleura & 1:320 Speckled \\
\hline \multirow[t]{2}{*}{$12 / 42 / \mathrm{F}$} & Serum & 1:80 Homogenous \\
\hline & Pleura & 1:40 Homogenous \\
\hline \multirow[t]{2}{*}{$13 / 42 / \mathrm{M}$} & Serum & 1:640 Speckled \\
\hline & Pleura & 1:80 Speckled \\
\hline \multirow[t]{2}{*}{$14 / 35 / F$} & Serum & 1:40 Speckled \\
\hline & Pleura & Negative \\
\hline \multirow{2}{*}{$15 / 21 / \mathrm{F}$} & Serum & 1:160 Homogenous \\
\hline & Pleura & Negative \\
\hline
\end{tabular}

ANA: antinuclear antibodies; F: female; M: male. 
level $\left(174 \mathrm{U} \cdot \mathrm{L}^{-1}\right)$. Antituberculous chemotherapy was instituted but pleuritis persisted. Elevated pleural ANA level and numerous LE cells in cytological smear confirmed the diagnosis of LE pleurisy. Antituberculous chemotherapy was discontinued and the patient had good response to steroid treatment.

In addition to the 11 patients with lupus serositis, a total of 145 patients with effusions of nonlupus aetiologies were also studied. Thirty-eight patients $(26 \%)$ had positive pleural or pericardial fluid ANA titre, and high titres $(\geq 1: 160)$ with different stain patterns were observed in 13 patients (table 3). Malignant or paramalignant effusion constituted 11 of these 13 fluid samples.

Patients 25 and 26 presented with unknown causes of massive pleural effusion. Thoracentesis performed on admission and the 14th hospitalized day yielded the same serosangious fluid. Very high ANA titres to 1:5,210 in pleural and pericardial fluid were detected (table 3 ) and lupus pleurisy was initially suspected. However, after serial work up, it was found that they did not meet the American Rheumatology Association criteria for SLE. Serial cytological examinations later confirmed the diagnosis of small cell carcinoma in patient 25 and showed reactive mesothelial cells without LE cells or malignant evidence in patient 26. Tumour marker analysis (carcinoembryonic antigen (CEA), carbohydrate antigen (Ca)19.9, CA 15.3) of fluid revealed a normal value. Patient 26 was later found to have a small anterior mediastinal tumour on chest computed tomography scan. Fine needle aspiration and Tru-cut biopsy with coloured doppler ultrasound guidance confirmed the diagnosis of thymic carcinoma $[8,9]$.

Twenty-six patients with pericardial effusion, but without clinical evidence of SLE, were also studied. Positive pericardial fluid ANA titre was noted in six $(23 \%)$ patients. Four of these pericardial effusions were associated with malignancy, one with tuberculosis and one with virus infection. Only two pericardial fluid samples had high ANA titre (160); one resulted from tuberculosis, one from malignancy (table 3).

In the 13 patients with high ANA titres in pleural or pericardial fluid, serum ANA titres were also measured. The pleural fluid or pericardial fluid to serum ANA ratio was $\geq 1$ except in three cases (patients 18, 19 and 22). Although 11 of these 13 effusions resulted from malignancy, only five effusions had proven malignant cells. The CEA levels were found to be elevated in eight effusions. The pleural invasion of tumours and CEA levels, therefore, has no specific correlation with ANA titres.

\section{Discussion}

This study demonstrates that all the pleurisy due to active lupus had high fluid ANA titres. It was also found that 13 of the 145 effusions $(9 \%)$ with nonlupus aetiologies had high fluid ANA titre and most of them were malignancy related effusions. Conversely, the pleural fluid ANA titre

Table 3. - Clinical data of patients without systemic lupus erythematosus but with high antinuclear antibodies (ANA) titre

\begin{tabular}{|c|c|c|c|c|c|c|c|}
\hline \multirow{2}{*}{$\begin{array}{l}\text { Case No./ } \\
\text { Age/Sex }\end{array}$} & \multirow[t]{2}{*}{ Clinical Dx } & \multirow{2}{*}{$\begin{array}{c}\text { Sources of } \\
\text { Samples }\end{array}$} & \multicolumn{3}{|c|}{ ANA titre and pattern } & \multirow{2}{*}{$\begin{array}{l}\text { Fluid CEA } \\
\mathrm{Ng}^{-1} \mathrm{~mL}^{-1}\end{array}$} & \multirow[t]{2}{*}{$\begin{array}{l}\text { Tumour } \\
\text { invasion } \\
\text { to pleura }\end{array}$} \\
\hline & & & 1 st ho & pitalized day & 14th hospitalized day & & \\
\hline \multirow[t]{3}{*}{$16 / 84 / \mathrm{F}$} & TBC pleuritis & Serum & $1: 320$ & Speckled & ND & 4 & - \\
\hline & TBC pericarditis & Pleura & $1: 320$ & Speckled & & 9.6 & \\
\hline & & Pericardial & $1: 160$ & Homogenous & & 8.5 & \\
\hline \multirow{2}{*}{$17 / 63 / \mathrm{M}$} & Bronchogenic Adeno $\mathrm{Ca}$ & Serum & $1: 160$ & Homogenous & ND & 28 & + \\
\hline & & Pleura & $1: 160$ & Homogenous & & 32 & \\
\hline \multirow[t]{2}{*}{$18 / 43 / \mathrm{M}$} & Bronchogenic Adeno $\mathrm{Ca}$ & Serum & $1: 320$ & Homogenous & ND & 117 & + \\
\hline & & Pleura & $1: 160$ & Homogenous & & 132 & \\
\hline \multirow[t]{2}{*}{ 19/85/M } & Amebiasis empyema & Serum & $1: 320$ & Speckled & ND & 1.2 & \\
\hline & & Pleura & $1: 160$ & Speckled & & 24 & \\
\hline \multirow[t]{2}{*}{$20 / 60 / F$} & Breast $\mathrm{Ca}$ & Serum & $1: 320$ & Homogenous & ND & 75 & - \\
\hline & & Pleura & $1: 320$ & Homogenous & & 32 & \\
\hline \multirow[t]{2}{*}{$21 / 56 / \mathrm{M}$} & Bronchogenic Adeno $\mathrm{Ca}$ & Serum & $1: 320$ & Homogenous & ND & 20 & - \\
\hline & & Pleura & $1: 320$ & Speckled & & 316 & \\
\hline \multirow[t]{2}{*}{$22 / 60 / \mathrm{M}$} & Bronchogenic squamous & Serum & $1: 320$ & Nucleolar & ND & 4.2 & - \\
\hline & cell $\mathrm{Ca}$ & Pleura & $1: 160$ & Nucleolar & & 5 & \\
\hline \multirow[t]{2}{*}{$23 / 65 / \mathrm{M}$} & Bronchogenic Adeno $\mathrm{Ca}$ & Serum & $1: 320$ & Speckled & 1:40 speckled & 50 & + \\
\hline & & Pleura & $1: 320$ & Speckled & 1:40 Speckled & 42 & \\
\hline \multirow{2}{*}{$24 / 41 / \mathrm{F}$} & Bronchogenic Adeno $\mathrm{Ca}$ & Serum & $1: 160$ & Speckled & ND & 18 & + \\
\hline & & Pleura & $1: 160$ & Speckled & & 132 & \\
\hline \multirow[t]{2}{*}{$25 / 54 / \mathrm{M}$} & Bronchogenic small & Serum & $1: 1280$ & Discrete & 1:320 Discrete & 8.4 & + \\
\hline & cell $\mathrm{Ca}$ & Pleura & $1: 5120$ & Discrete & 1:640 Discrete & 5.4 & \\
\hline \multirow[t]{3}{*}{$26 / 64 / F$} & Malignant Thymic Ca & Serum & $1: 320$ & Speckled & 1:320 Speckled & 1.1 & - \\
\hline & & Pleura & $1: 1280$ & Speckled & 1:640 Speckled & 2.2 & \\
\hline & & Pericardial & $1: 640$ & Speckled & 1:320 Speckled & 0.5 & \\
\hline \multirow{2}{*}{ 27/28/M } & Bronchogenic squamous & Serum & $1: 160$ & Speckled & ND & 7.2 & - \\
\hline & cell $\mathrm{Ca}$ & Pleura & $1: 160$ & Speckled & & 6.5 & \\
\hline \multirow{2}{*}{$28 / 60 / F$} & Breast $\mathrm{Ca}$ & Serum & $1: 320$ & Homogenous & ND & 46 & - \\
\hline & & Pleura & $1: 320$ & Homogenous & & 38 & \\
\hline
\end{tabular}

Dx: diagnosis; CEA: carcinoembryonic antigen; F: female; TBC: tuberculosis; ND: not done; M: male; Ca: carcinoma. 
was positive in low fibres only $(\leq 1: 80)$ in six of the 28 patients $(21 \%)$ with parapneumonic effusion or empyema.

The detection and application of ANA testing has been used in undiagnosed pleurisy via the development of a human cell line substrate (e.g. HEP-2), which is more sensitive than animal cell lines [11]. However, the significance of ANA titre in pericardial effusion has never been reported previously [11] and only three articles had been published that focused on ANA in pleural fluid (table 4). This study differed from previous studies in its prospectve design to collect the pleural and pericardial fluid over a 3 -yr period for ANA detection by the HEP-2 human epithelial cell line. LeECHAWENGWONG et al. [2] first reported the significance of pleural fluid ANA titre. In that study, seven of the 100 pleural fluid samples had positive ANA results and all of the seven patients were diagnosed as having pleurisy due to active lupus. Good et al. [3] later in 1983, examined the ANA titres of 85 pleural fluid samples. Lupus pleurisy was diagnosed in 14 of the 85 pleural effusions. The 14 positive pleural fluid ANA titres showed a broad range, 1:40-1:2,560. In the 71 patients with pleural effusions of nonlupus aetiologies, the pleural fluid ANA was all negative or low titre $(\leq 1: 80)$. Both LEECHEWENGWONG et al. [2] and Good et al. [3] concluded that high ANA titre $(\geq 1: 160)$ of pleural effusion is found only in lupus pleurisy. However, KHARE et al. [5] recently reported that eight of 74 patients $(10.8 \%)$ without clinical evidence of SLE had a positive fluid ANA and three of them $(4 \%$, one congestive heart failure $1: 160$, one parapneumonic effusion 1:640 and one paramalignant effusion 1:160) had high fluid ANA titres $(\geq 1: 160)[5,6]$. KHARE et al. [5] concluded that occasionally patients with inflammatory pleural effusions may have ANA titre $\geq 1: 160$ (but $\leq 1: 640$ ) in the absence of lupus pleurisy. These results were in contrast to previous reports (table 4). Since then, there have been no studies performed to clear up the controversy $[6,11]$. In the current series, 32 of the 119 pleural effusions (27\%) and six of the 26 pericardial effusions $(23 \%)$ without clinical evidence of SLE had positive results for ANA. High pleural or pericardial fluid titres were seen in 13 of the 145 patients (9\%) with effusion due to nonlupus aetiology. The pleural fluid ANA titre was positive but low $(\leq 1: 80)$ in six of the 28 patients $(21 \%)$ with parapneumonic effusion or empyema (table 1). High pleural fluid ANA titres were not seen in any patient with parapneumonic effusion or congestive heart failure.

On the other hand, malignant or paramalignant effusion constituted 11 of the 13 effusions with high fluid ANA titres. Furthermore, two of the 11 malignant effusions had highly elevated $(\geq 1: 1280)$ ANA titres and were therefore considered as lupus pleurisy initially (table 3). Although patients with tumours may have low ANA titres in sera of $\sim 1: 40$, ANA titres $>1: 640$ occur only occasionally, mostly in patients with lymphoma or cancer of the lung, breast, or colon $[12,13]$. This raises the question of whether high ANA titres might reflect carcinogenesis like carcinoembryonic antigen [14]. There have been only a few studies that have discussed ANA titres in malignant effusions [4, 11]. The current results revealed that in cases of high pleural or pericardial fluid ANA titres, malignant effusion should firstly be considered if they do not meet the criteria of SLE even as high as 1:5,120 (tables 3 and 4). Statistically, the positive predictive value of high fluid ANA for malignancy in nonlupus patients was high $(84.6 \%)$.

The parameter of pleural fluid to serum ANA ratio has also been discussed. Good et al. [3] found that most pleural fluid to serum ANA ratio was $>1$ in lupus pleurisy. In contrast, the ratio was $<1$ in patients with nonlupus pleurisy. In the current study, all 11 patients with either pleural, pericardial effusion or ascites with clinical diagnosis of active lupus serositis had high fluid ANA titre $(\geq 1: 160)$, but in only five patients $(45 \%)$ was the pleural fluid or pericardial fluid to serum ANA ratio $\geq 1$ (table 2). Conversely, 10 of 13 patients with high fluid ANA titres due to nonlupus aetiologies had a pleural or pericardial fluid to serum ANA titres ratio $\geq 1$. The current results suggested that ANA ratio of pleural or pericardial fluid to serum is neither a sensitive nor a specific diagnostic tool to identify the lupus serositis.

BECK [15] first reported different patterns of nuclear immunofluorescence and this variability in staining patterns has been also observed in the sera of patients with SLE [11]. KHARE et al. [5] reported that the homogeneous staining pattern in pleural fluid was predominately found in patients with lupus pleuritis. However, the current study revealed that only five of the 11 patients with lupus serositis had a homogeneous staining pattern. Four of the 13 patients with nonlupus serositis also had high ANA

Table 4. - Results of different studies of antinuclear antibodies (ANA) in pleural fluid

\begin{tabular}{|c|c|c|c|c|c|}
\hline $\begin{array}{l}\text { First author } \\
\text { [Ref.] }\end{array}$ & $\begin{array}{l}\text { Assay } \\
\text { used }\end{array}$ & $\begin{array}{l}\text { No. of pleural } \\
\text { fluid samples }\end{array}$ & $\begin{array}{l}\text { Disease associated } \\
\text { with HPF ANA }\end{array}$ & $\begin{array}{l}\text { Positive fluid } \\
\text { ANA* \% }\end{array}$ & $\begin{array}{l}\text { PPV of high fluid } \\
\text { ANA for malignancy* \% }\end{array}$ \\
\hline LEECHAWENGWONG [2] & $\begin{array}{l}\text { Nonhuman derived } \\
\text { animal cell line }\end{array}$ & 100 & SLE & 0 & 0 \\
\hline GoOD [3] & $\begin{array}{l}\text { Nonhuman derived } \\
\text { animal cell line }\end{array}$ & 85 & SLE & 0 & 0 \\
\hline KHARE [5] & HEP-2 & 82 & $\begin{array}{c}\text { SLE } \\
\text { Malignancy } \\
\text { Pneumonia } \\
\text { CHF }\end{array}$ & 11 & 33 \\
\hline WANG [this study] & HEP-2 & 126 & $\begin{array}{c}\text { SLE } \\
\text { Malignancy } \\
\text { Tuberculosis } \\
\text { Amebiasis }\end{array}$ & 27 & 85 \\
\hline
\end{tabular}

HPF: high pleural fluid; PPV: positive predictive value; SLE: systemic lupus erythematosus; HEP-2: human epithelial cell line; CHF: congestive heart failure. ${ }^{*}$ : in nonlupus patients. 
titres of homogeneous staining pattern. Furthermore, it is well known to serologists that single sera or fluid can show multiple ANA patterns depending on dilution [11]. From these observations, the current authors suggested that the homogeneous staining pattern of ANA appears obsolete in identifying lupus pleurisy.

Another interesting finding not mentioned in previous reports is that three of the 11 patients with malignant or paramalignant effusions received second thoracentesis 2 weeks after the first thoracentesis and decreased fluid ANA titre was noted without chemotherapy or radiotherapy. The real meaning of ANA titre change in pleural and pericardial fluid is not well understood, although disappearance of elevated serum ANA titres has been reported in cases of hepatocellular carcinoma after treatment [16]. However, the current findings of decreased serum and fluid ANA titres might support the hypothesis that ANA diffused from serum to pleura due to removal of antigen by thoracentesis.

It is concluded that high fluid antinuclear antibodies titres $(\geq 1: 160)$ in systemic lupus erythematosus patients with acute pleurisy suggests that the pleurisy is secondary to active lupus. However, high antinuclear antibodies titres of pleural or pericardial effusion is not diagnostic of lupus serositis, even if the titre is as high as 1:5,120. Nonlupus patients with high fluid antinuclear antibodies titres warrant searching for a malignancy first. The staining pattern of antinuclear antibodies and pleural or pericardial fluid antinuclear antibodies titres to serum antinuclear antibodies titre ratio of 1 are not reliable clues to identify lupus serositis.

\section{References}

1. Slater CA, Davis RB, Shmerling RH. Antinuclear antibody testing: a study of clinical utility. Arch Intern Med 1996; 156: 1421-1425.

2. Leechawengwong M, Berger HW, Sukumaran M. Diagnostic significance of antinuclear antibodies in pleural effusion. Mt Sinai J Med 1979; 46: 137-139.

3. Good JT Jr, King TE, Antony VB, Sahn SA. Lupus pleuritis: clinical features and pleural fluid characteristics with special reference to pleural fluid antinuclear antibodies. Chest 1983; 87: 714-718.

4. Light RW. Pleural diseases. 3rd Edn. Baltimore, MD, USA, Williams \& Wilkins, 1995.

5. Khare V, Baethge B, Lang S, Wolf RE, Campbell GD. Antinuclear antibodies in pleural fluid. Chest 1994; 106 : 866-871.

6. Quismorio FP Jr. Pulmonary manifestations of systemic lupus erythematosus. In: Wallace DJ, Hahn BH, eds. Dubois' lupus erythematosus. 5th Edn. Baltimore, MD, USA, Lea \& Febiger, 1997; pp. 673-692.

7. Wang DY, Chang DB, Kuo SH, Yang S, Shiah DC, Chou HT. Systemic lupus erythematosus presenting as pleural effusion: report of a case. J Formos Med Assoc 1995; 94: 746-749.

8. Wang DY, Kuo SH, Chang DB, Yang PC, Lee YC, Hsu HC. Fine needle aspiration cytology of thymic carcinoid tumor. Acta Cytol 1995; 39: 423-427.

9. Yang PC, Chang DB, Yu CJ, Lee YC, Wu HD, Kuo SH. Ultrasound-guided core biopsy of thoracic tumors. Am Rev Respir Dis 1992; 146: 763-767.

10. Wang DY, Chang DB, Kuo SH, Yang PC, Lee YC, Hsu HC. Carcinoid tumours of the thymus. Thorax 1994; 49: 357-360.

11. Harley JB, Reichlin M. Antinuclear antibodies: an overview. In: Wallace DJ, Hahn BH, eds. Dubois' lupus erythematosus. 5th Edn. Baltimore, MD, USA, Lea \& Febiger, 1997; 397-405.

12. Thomas C, Robinson JA. The antinuclear antibody test. Postgrad Med 1993; 94: 55-66.

13. Zuber M. Positive antinuclear antibodies in malignancies. Ann Rheum Dis 1992; 51: 573-574.

14. Wang DY, Knyba RE, Bulbrook RD, Millis RR, Hayward JL. Serum carcinoembryonic antigen in the diagnosis and prognosis of women with breast cancer. Eur J Cancer Clin Oncol 1984; 20: 25-31.

15. Beck JS. Variations in the morphological patterns of autoimmune fluorescence. Lancet 1961; 1: 1203-1205.

16. Imai H, Ochs RL, Kiyosawa K, Furcuta S, Nahamura RM, Tan EM. Nucleolar antigens and autoantibodies in hepatocellular carcinoma and other malignancies. $\mathrm{Am} \mathrm{J}$ Pathol 1992; 140: 859-870. 